Please do not remove this page

RMIT

UNIVERSITY

\title{
Analysis of workflow variability and its impacts on productivity and performance in construction of multistory buildings
}

Arashpour, Mohammadreza; Arashpour, Mehrdad

https://researchrepository.rmit.edu.au/esploro/outputs/9921862430601341/filesAndLinks?institution=61RMIT_INST\&index=null

Arashpour, M., \& Arashpour, M. (2015). Analysis of workflow variability and its impacts on productivity and performance in construction of multistory buildings. Journal of Management in Engineering, 31(6), 1-9. https://doi.org/10.1061/(ASCE)ME.1943-5479.0000363

Document Version: Accepted Manuscript

Published Version: https://doi.org/10.1061/(ASCE)ME.1943-5479.0000363

Repository homepage: https://researchrepository.rmit.edu.au

(C) ASCE

Downloaded On 2023/04/26 23:38:07 +1000

Please do not remove this page 
Thank you for downloading this document from the RMIT Research Repository.

The RMIT Research Repository is an open access database showcasing the research outputs of RMIT University researchers.

RMIT Research Repository: http://researchbank.rmit.edu.au/

\section{Citation:}

Arashpour, M and Arashpour, M 2015, 'Analysis of workflow variability and its impacts on productivity and performance in construction of multistory buildings', Journal of Management in Engineering, vol. 31, no. 6, pp. 04015006-1-04015006-9.

See this record in the RMIT Research Repository at:

https://researchbank.rmit.edu.au/view/rmit:33178

Version: Accepted Manuscript

Copyright Statement: (C) ASCE

Link to Published Version:

http://dx.doi.org/10.1061/(ASCE)ME.1943-5479.0000363

\section{PLEASE DO NOT REMOVE THIS PAGE}




\section{Analysis of workflow variability and its impacts on 2 productivity and performance in construction production}

3 Mohammadreza Arashpour $^{1}$ and Mehrdad Arashpour, S.M.ASCE ${ }^{2}$

\section{Abstract}

5 The meeting of milestones presents a constant challenge in construction projects. One root cause

6 behind this challenge is the presence of variability in the project workflow. In fact, impacts of

7 variability at both trade contractor level and project level remain difficult to manage. This paper aims

8 to analyze impacts of variability in the workflow caused by rework and fluctuating work quantities.

9 Towards this end, production data of two residential construction projects were collected and a mixed

10 method of mathematical and simulation modeling was used in order to analyze performance and

11 productivity at both trade and project levels. Performance metrics such as completion times, work-in-

12 process levels and delays were then measured in different real-life production scenarios. The findings clearly show that the workflow variability significantly downgrades performance metrics by inflated completion times, longer queues of uncompleted jobs and excessive delays, resulting in the productivity loss. This work contributed to the body of knowledge in engineering management by enhancing the insight into workflow variability and its impacts on tangible performance measures. The results clearly show that productivity and performance in the construction production can be improved by stabilizing the workflow in the interconnected network of trade contractors.

CE Database subject headings: Engineering productivity; Lean construction; Project workflows

Keywords: Construction engineering; Discrete event simulation, Lean production; Optimization; Residential project; Productivity and performance; Project management; Pull and push workflows; Rework; Variability; Workflow stability

${ }^{1}$ Lecturer, Faculty of Engineering, Azad University, Tehran 14778, Iran, Email: m.arashpour@azad.ac.ir 
29 Construction worksites are dynamic environments and subject to a high level of variability. External

30 variability is mainly caused by factors outside the project environment such as extreme weather

31 conditions (El-Adaway 2012) and non-stationary market demand (Ahmad 1999, Barriga, Jeong et al.

32 2005). Internal variability can be resulted by different sources such as unstable workflows (Laufer,

33 Woodward et al. 1999, Palaniappan, Sawhney et al. 2007), workforce motivation (Han, Park et al.

34 2008, Arashpour, Shabanikia et al. 2012), and quality issues causing rework (Josephson, Larsson et al.

35 2002, Love and Smith 2003). Fig.1 illustrates production problems in construction and different

36 approaches to model them.

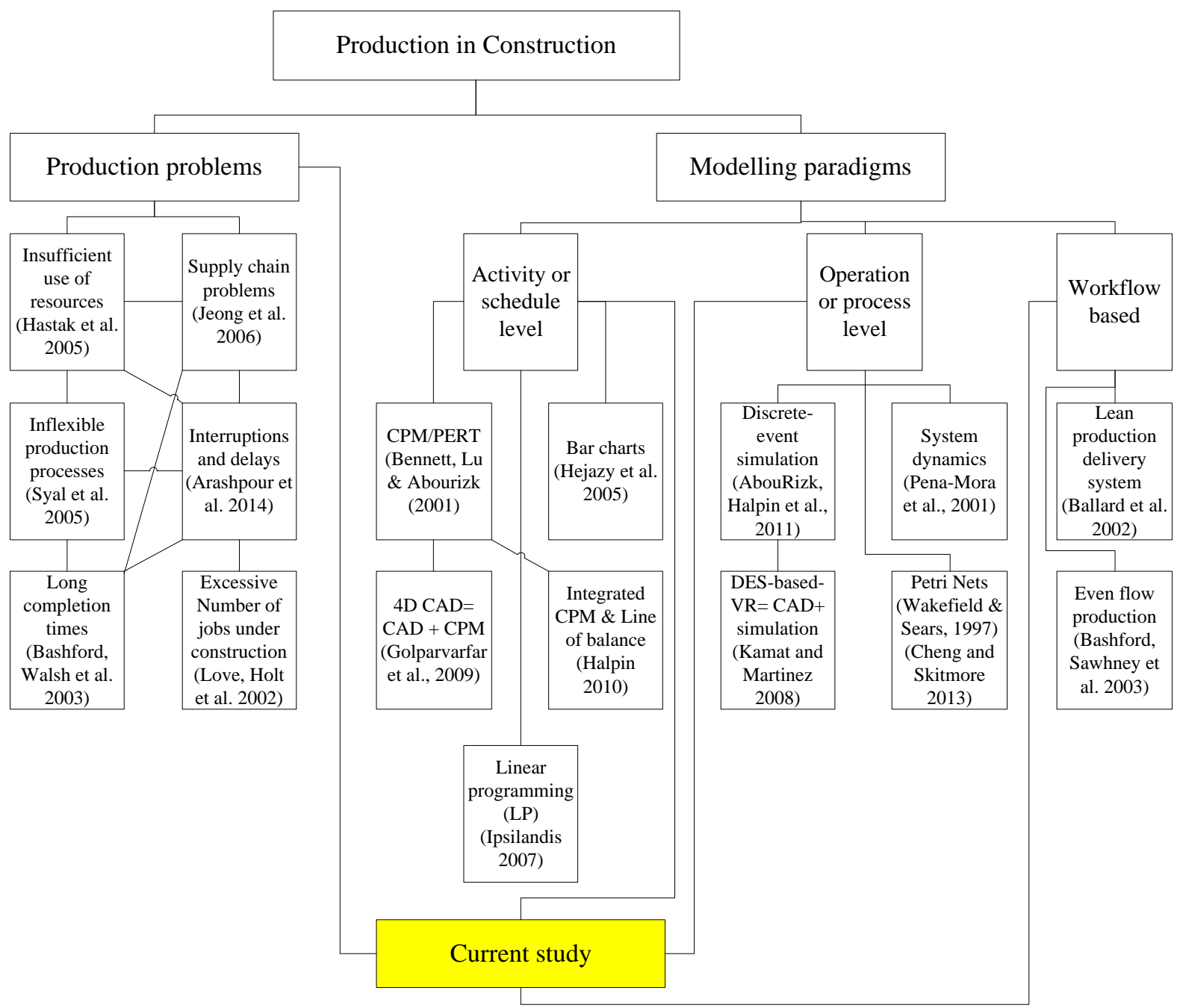

Fig. 1. Problems caused by variability in construction production and Modeling paradigms to address them 
As can be seen in Fig.1, different paradigms have been used to model and address the high level of variability in construction and the resulting problems. The first and most popular modeling approach is activity or schedule based with modeling tools such as Critical Path Method (CPM) and Project Evaluation and Review Technique (PERT). The second approach is operation or process based modeling that uses Discrete Event Simulation (DES) as the main modeling strategy. Finally, the youngest modeling paradigm of all relies on workflow management. Lean production delivery system and even flow production are categorized in this stream.

In the presence of variability, it is not always possible to increase the production rate by accelerating bottleneck processes. Research in the international level has shown that increasing the availability of construction resources and levels of employment in the industry have not improved the productivity significantly (Mawhinney 2008, Mubarak 2010). Furthermore, it is often not possible to increase the availability of labor resources over a short period as there are strong barriers of entry into some trades. For example, a plumber or electrician needs to work as an apprentice for a couple of years before becoming a licensed trade. These limitations and the need to optimize the performance and productivity in the residential construction motivate research on process design and workflow analysis and explain the rationale behind the present study.

In the construction engineering and management literature, effects of variability on production have been investigated (Shoura and Singh 1997, Liu, Ballard et al. 2011). However, holistic research that considers impacts of workflow variability on productivity and performance at both project and trade contractor levels is sparse (Yung and Yip 2010, Yu 2011).

In order to bridge this gap, this investigation collected the production data of two residential builders. Impacts of workflow variability on tangible performance metrics such as completion time, delays and construction capacity were measured and analyzed. A mathematical approach was used to analytically model the performance of trade contractors. Then, discrete event simulation was utilized in order to model and analyze the interconnected network of trades, as construction project networks are too complex to be solved analytically. 


\section{Research methodology} Lacouture, Süer et al. 2009).

The findings show that workflow instability has significant impacts on productivity and performance in the construction production. Inflated completion times, excessive delays, and long queues of uncompleted jobs are among the observed consequences. These negative impacts can be reduced by stabilizing the workflow in the trade contractor network. Variability can also be reduced by avoiding pushing new jobs into the system regardless of resource utilization levels.

The purpose of this investigation is to analyze the effects of workflow variability on tangible performance measures of construction projects. After collecting the production data of two residential builders and at the first stage, single trade contractor processes were analytically modeled in order to analyze the performance metrics at this level. Performance metrics of different trades such as bricklayers and plumbers were measured and analyzed using the principles of the queuing theory.

At the second stage of the research, the entire project network was modeled using discrete event simulation (DES) in order to keep track of tangible performance metrics at the project level. Care was taken in order to build accurate models that reflect complex interactions in construction sites and workflow within the interlinked network of trade contractors. In reality, trade contractors are not operating independently and the completed work of a given trade is required for a successor trade in order to proceed. Simulation experiments were designed in order to analyze real-life what-if production scenarios, each with different levels of workflow variability.

The application of a mixed methodology, in which both mathematical and simulation modeling are conducted, provides a robust research approach in the field of construction engineering and management (AbouRizk and Hague 2009, Lee, Fung et al. 2013). Simulation has been used as a decision support tool in the construction engineering literature (Back and Bell 1995, Min and Bjornsson 2008). Furthermore, comparative analysis of simulation and of mathematical models provides a measure of validation and test the accuracy of the developed models (Wang 2004, Castro- 


\section{Impacts of workflow variability on the productivity at the trade level}

91 Data obtained in previous studies show that variability in construction processes degrades the

92 performance measures of trade contractors (Tommelein, Riley et al. 1999, Arashpour, Wakefield et al.

93

94

95

96

97 2013). When variability is present, construction process times are no longer deterministic. Furthermore, variable processes decrease the capacity of the production network and inflate the construction duration (Doloi, Iyer et al. 2011). Rework or re-entrant flow is an important cause of variability in construction projects that causes processes to be unpredictable (Love and Smith 2003). In construction projects, rework can be caused by construction faults discovered through formal/compulsory stage inspections or informal worksite observations. Another type of rework is client-related rework, which is caused by changes in project scope, plan and design by the client (Hwang, Zhao et al. 2013). In order to analyze the impacts of workflow variability on production and performance, production data of two residential builders were collected. Details of construction processes in the worksites were captured during numerous site visits. Snapshots of the two worksites are shown in Fig.2.
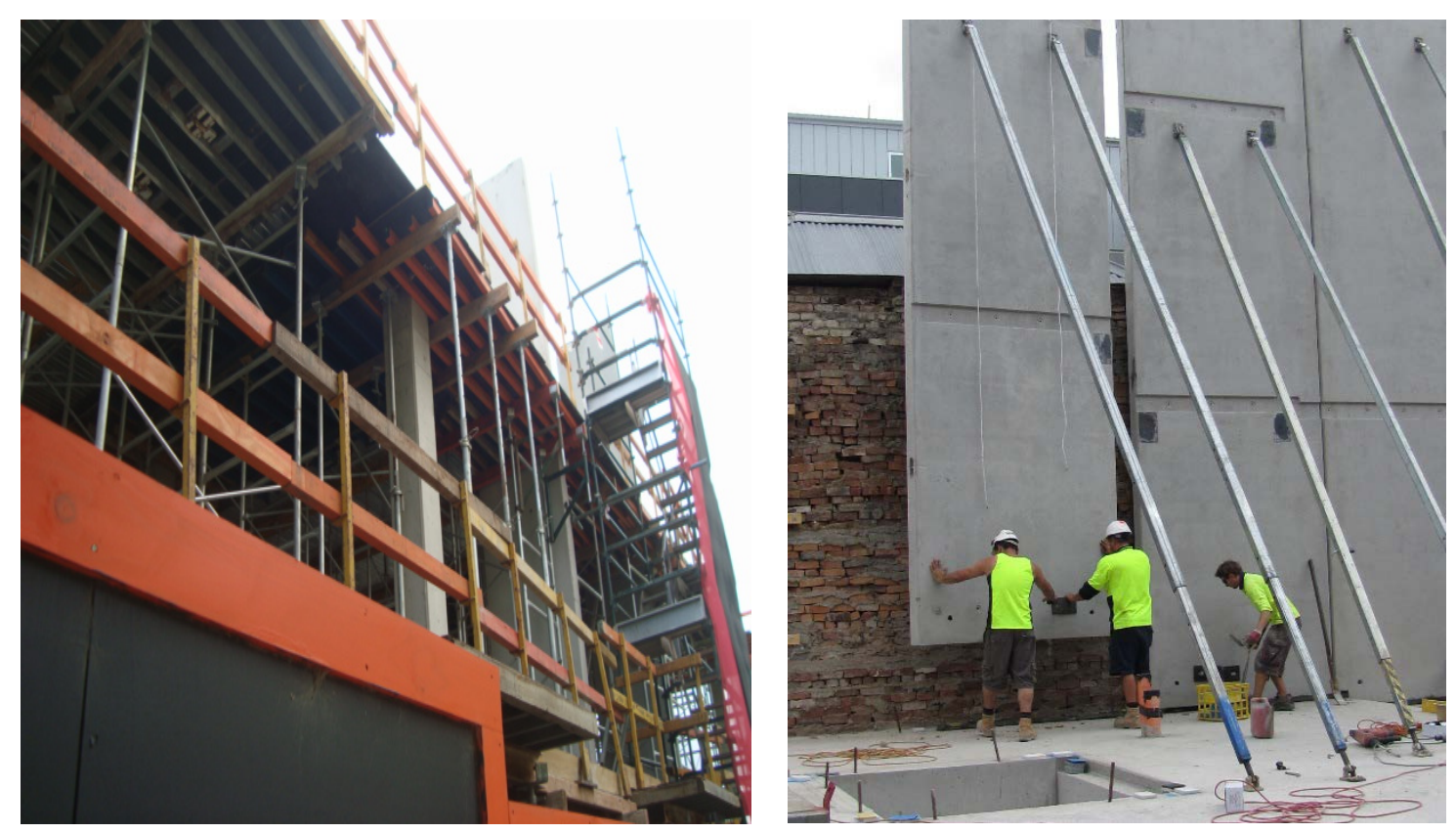

Fig. 2. Residential construction worksites (image by the first author)

Rework data including the number of instances and durations were collected. The long-term probability of having a quality issue, which results in rework, is different for trades. When a 
construction process is subject to rework, trade contractors have to return to the same place multiple times. For example, the plumbing trade had to come back to the worksite in $25 \%$ of time in order to rectify the faults (for a total of 40 jobs completed in different apartments). Based on the site observations, the plumbing trade needed an average of $t_{0}=3$ days to complete tasks in one apartment. Fig. 3 shows a schematic illustration of rework loop in the plumbing process within the interconnected trade network.

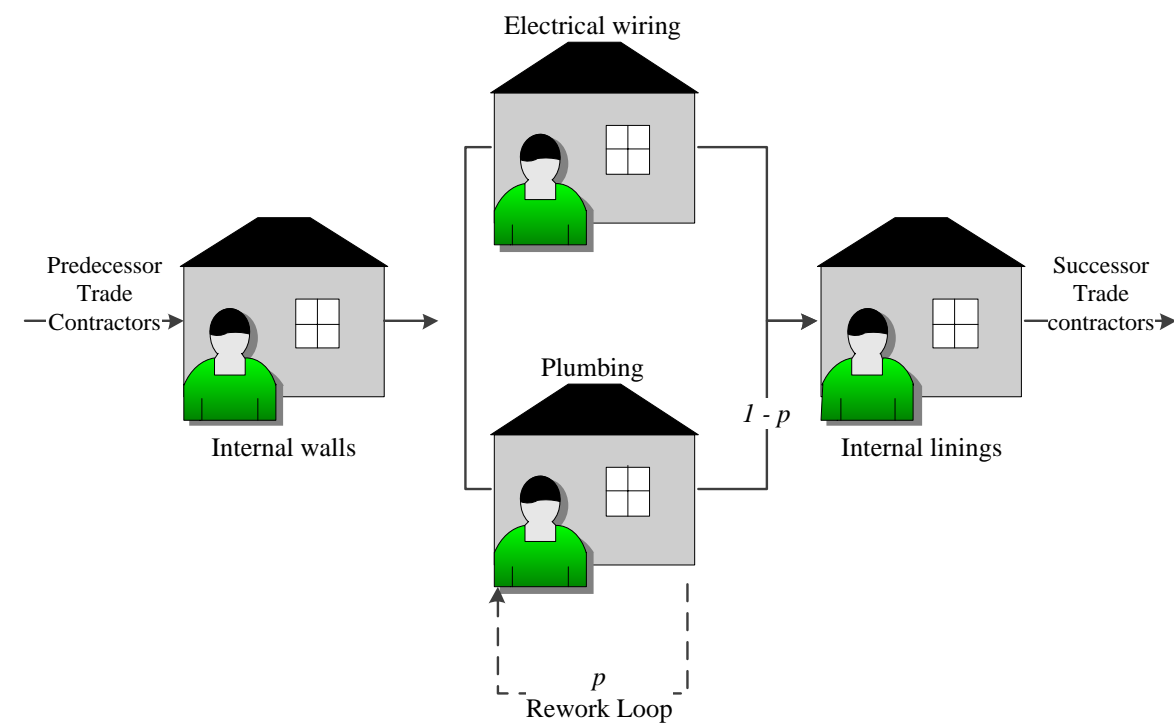

\section{Fig. 3. Rework loop in the plumbing process}

Understandably, effective process time $\left(t_{e}\right)$ is inflated upon the existence of rework and can be computed using Eq. (1):

$$
t_{e}=\frac{t_{0}}{1-p}
$$

In Eq. (1), $t_{0}$ is the average processing time and $p$ is the probability of rework. For instance, for the plumbing trade with $t_{0}=3$ days and $p=25 \%$, the effective process time will be $t_{e}=4$ days.

Utilization level of trade contractors is another important performance measure in the construction production and was computed using Eq. (2):

$$
u=\frac{t_{e}}{t_{a}}
$$


In Eq. (2), $t_{a}$ is the average time between activity starts and $u$ is the utilization level that adopts

132 values between 0 and 100\%. Having an effective process time of $t_{e}=4$ days, the utilization level for the plumbing trade will be equal to $80 \%$ provided that new jobs are started every five days.

At the first stage of the analysis, trade contractors with different rework rates were compared when other production variables such as average time between activity starts were fixed. Based on this premise and the collected data, eight observed rework probabilities of $2 \%, 7 \%, 10 \%, 13 \%, 18 \%, 25 \%$, $30 \%$ and $33 \%$ were compared. Tangible performance measures for individual trade contractors were then computed. Table 1 shows the results of this analysis.

Table 1. Trade-level performance measures with different rework probabilities (p)

\begin{tabular}{lcccccccc}
\hline Parameter & \multicolumn{7}{c}{ Average time between activity starts $\left(\boldsymbol{t}_{\boldsymbol{a}}\right)=\mathbf{5}$ days } \\
\hline Probability of rework $(\boldsymbol{p})$ & $2 \%$ & $7 \%$ & $10 \%$ & $13 \%$ & $18 \%$ & $25 \%$ & $30 \%$ & $33 \%$ \\
Effective Process time $\left(\boldsymbol{t}_{\boldsymbol{e}}\right)$ & 3.06 & 3.23 & 3.33 & 3.45 & 3.66 & 4.00 & 4.29 & 4.48 \\
Effective process rate $\left(\boldsymbol{r}_{\boldsymbol{e}}=\frac{\mathbf{1}}{\boldsymbol{t}_{\boldsymbol{e}}}\right)$ & 0.33 & 0.31 & 0.30 & 0.29 & 0.27 & 0.25 & 0.23 & 0.22 \\
Utilization level $\left(\boldsymbol{u}=\frac{\boldsymbol{t}_{\boldsymbol{e}}}{\boldsymbol{t}_{\boldsymbol{a}}}\right)$ & 0.61 & 0.65 & 0.67 & 0.69 & 0.73 & 0.80 & 0.86 & 0.90 \\
\hline
\end{tabular}

As can be seen in table 1, both effective process times and utilization rates grow as the rework probability increases. However, effective process rates of individual trades decreases from 0.33 to 0.22 , which shows an increasing amount of waste in the production as a result of workflow variability caused by rework.

Although in the analyzed scenarios $t_{a}$ is controlled, the utilization level of the trade increases nonlinearly proportional to the rework probability. In other words, the workload of the trade contractor increases despite the fact that the trade contractor does not start new jobs more frequently. This overwhelms the trade contractor when $p>1-\left(t_{0} / t_{a}\right)$. As can be seen in table 1 , utilization level of the trade contractor hits a peak of $90 \%$ as the rework rate rises to $33 \%$. When the utilization level is close to $100 \%$, the trade cannot catch up anymore and successor trades will be delayed.

Understandably, the completion time $(C T)$ of a variable process is always longer than the effective process time as the rework loop may repeat more than once. Furthermore, $C T$ is proportional to the total variability level $(V)$, resource utilization level $(U)$, and processing time $(T)$. Assuming that 
147 discrete processes (Kingman 1992) can be used to compute the completion time of the individual 148 trade process. Interested readers can refer to Arashpour, Wakefield et al. (2014) for a more detailed 149 treatment of the analytical modeling approach.

$150 \quad \sigma_{\mathrm{e}}^{2}=\frac{\sigma_{0}^{2}}{1-p}+\frac{p t_{0}^{2}}{(1-p)^{2}}$

151 In Eq. (2), $\sigma_{0}$ is the standard deviation of the normal processing time. The relative variability measure 152 of primary interest is the coefficient of variation $(\mathrm{CV})$ that is computed by Eq. (3) as suggested by 153 Hopp and Spearman (2008) and Trietsch and Baker (2012):

$154 C V^{2}=\frac{\sigma_{e}^{2}}{t_{e}^{2}}=\frac{(1-p) \sigma_{0}^{2}+p t_{0}^{2}}{t_{0}^{2}}$

155 The squared coefficient of variation $\left(C V^{2}\right)$ compares the level of variability in trade contractor 156 processes considering both the average processing time (first moment) and variance (second moment).

157 Finally, the average completion time for jobs can be computed using Eq. (4).

$158 \quad C T=\frac{1+C V^{2}}{2} \frac{u}{1-u} t_{e}+t_{e}$

159 Surface chart in Fig. 4 illustrates the results of completion time calculations for different rework 160 probabilities. 


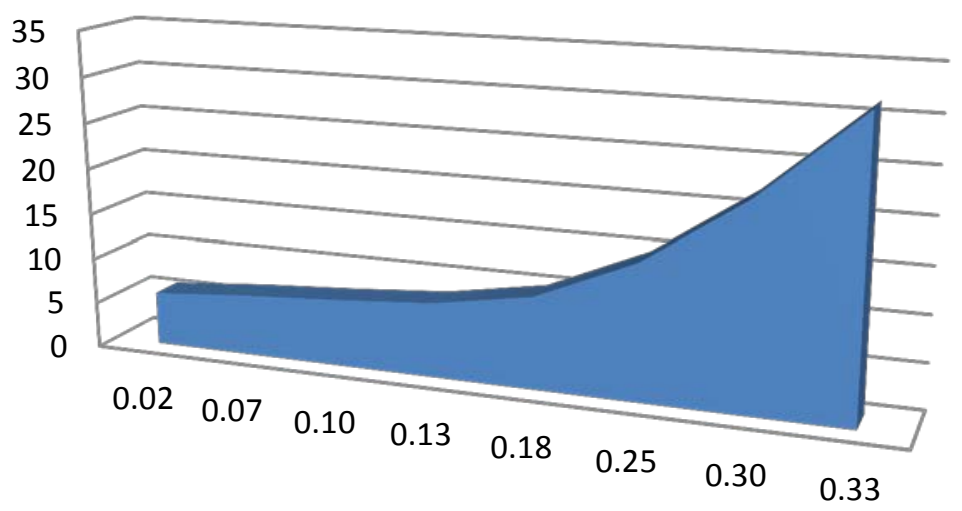

Process completion time (days)

5.79

\begin{tabular}{|c|c|c|c|c|c|c|}
\hline 0.07 & 0.10 & 0.13 & 0.18 & 0.25 & 0.30 & 0.33 \\
\hline 6.67 & 7.33 & 8.15 & 10.00 & 14.67 & 22.00 & 31.43 \\
\hline
\end{tabular}

Fig. 4. Process completion time for the trade contractors with different probability of rework

As can be seen in Fig. 4, completion time increases exponentially when probability of rework grows.

The findings of analytical modeling at the trade level, extend those of Jarkas and Radosavljevic (2013) and Ummer, Maheswari et al. (2014), confirming the negative impacts of workflow variability on the production and performance in the construction production.

\section{Impacts of decreasing the interval between starts of new activities at the}

\section{trade level}

In the first analysis, the average interval between activity starts $\left(t_{a}\right)$ was controlled for. This stabilizes the workflow in the trade contractor network. However, it is not always the case in real-world construction. Intervals between activity starts are variable in order to meet the project deadlines and make up for the lengthened completion time induced by factors such as rework. Consider the case that start intervals are reduced to four days instead of five days in the base case. Table 2 shows the performance measures in this scenario.

Table 2. Trade-level performance measures resulting from reduced activity start intervals $\left(t_{a}\right)$

\begin{tabular}{lccccccccc}
\hline Parameter & \multicolumn{8}{c}{ Average time between activity starts $\left(\boldsymbol{t}_{\boldsymbol{a}}\right)=\mathbf{4}$ days } \\
\hline Probability of rework $(\boldsymbol{p})$ & $2 \%$ & $7 \%$ & $10 \%$ & $13 \%$ & $18 \%$ & $25 \%$ & $30 \%$ & $33 \%$ \\
Effective Process time $\left(\boldsymbol{t}_{\boldsymbol{e}}\right)$ & 3.06 & 3.23 & 3.33 & 3.45 & 3.66 & 3.95 & 4.29 & 4.48 \\
Effective process rate $\left(\boldsymbol{r}_{\boldsymbol{e}}=\frac{\mathbf{1}}{\boldsymbol{t}_{\boldsymbol{e}}}\right)$ & 0.33 & 0.31 & 0.30 & 0.29 & 0.27 & 0.25 & 0.23 & 0.22 \\
Utilization level $\left(\boldsymbol{u}=\frac{\boldsymbol{t}_{\boldsymbol{e}}}{\boldsymbol{t}_{\boldsymbol{a}}}\right.$ & 0.77 & 0.81 & 0.83 & 0.86 & 0.91 & 0.99 & $>1$ & $>1$ \\
\hline
\end{tabular}


179 As is evident in table 2, increasing the rework probability and decreasing the interval between activity starts have significant impacts on the performance of the trade contractor.

In order to test if both rework probability and reducing the activity start interval have significant impacts on the process completion time, an analysis of variance was conducted using the General Linear Model (GLM). Probability plots of process completion times show that the data is normally distributed and requirements for analysis of variance are satisfied. Fig.5 illustrates the probability plots of process completion times.

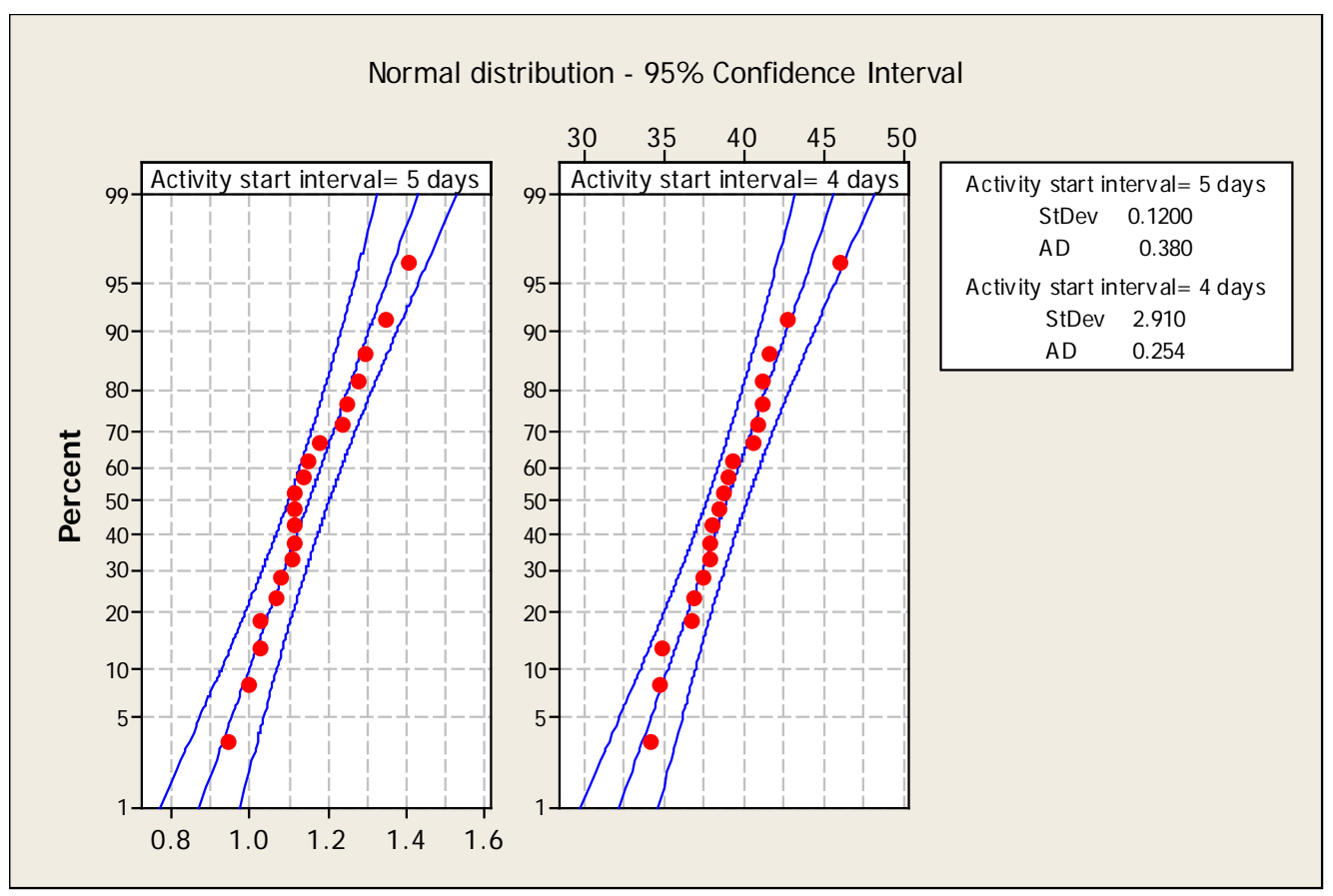

Fig. 5. Distribution of process completion times

In the general linear model (GLM), response variable is the completion time and factors are rework probability $(p)$ and time between activity starts $\left(t_{a}\right)$. As can be seen in table 3 , results of analysis of variance show that both factors have significant impacts on the process completion times.

Table 3. Results of general linear model (GLM): completion times versus rework probability and rate of job assignment

\begin{tabular}{lllllll}
\hline Source & $\begin{array}{l}\text { Degree of } \\
\text { freedom }\end{array}$ & $\begin{array}{l}\text { Sequential sums } \\
\text { of squares }\end{array}$ & $\begin{array}{l}\text { Adjusted sums } \\
\text { of squares }\end{array}$ & $\begin{array}{l}\text { Adjusted } \\
\text { means squares }\end{array}$ & F- statistic & P-value \\
\hline $\begin{array}{l}\text { Rework } \\
\text { probability }(\boldsymbol{p})\end{array}$ & 7 & 6746752 & 6192340 & 2064113 & 1068.78 & 0.006 \\
Activity start & 1 & 52574 & 52574 & 26287 & 130.61 & 0.005 \\
\hline
\end{tabular}


194

195

interval $\left(t_{a}\right)$

In table 3, P-values for both factors are less than the critical value $(\alpha=0.05)$. Both P-value and Fstatistic show that the process completion times significantly differ when rework probability and activity start intervals are variable.

Coming back to results in tables 1 and 2, a striking difference is noted in the resource utilization level. Provided that $t_{a}$ is equal to four days, trades can catch up until rework probabilities is equal to or less than 25 per cent. After this point, the resource utilization level reaches 100 per cent and the production network becomes unstable. The results show that upon the presence of workflow instability (rework), even a small increase in the rate of activity starts can overwhelm the contractors, causing successor trades to be delayed. This can result in major project schedule overruns, which will be analyzed in the next section.

The findings extend those of Mahamid, Bruland et al. (2012) and Golob, Bastič et al. (2013) (Mahamid, Bruland et al. 2012, Golob, Bastič et al. 2013), indicating that workflow instability results in inflated completion times and poor performance measures.

Given that residential construction project networks are too complex, not all tangible performance metrics can be computed analytically. The simulation study described in the next section aims to address this limitation. Comparing results of two modeling approaches also provides a validation measure.

\section{Impacts of workflow variability on the productivity at the project level}

The previous analytical results revealed the negative impact of workflow variability on the trade-level performance. This part of the investigation aims to analyze variability impacts on the project-level performance metrics. To this end, simulation experiments were designed and run in order to analyze the data. 
The project-level statistics of particular interest are completion time $(C T)$, value added $(V A)$ time, queuing (delay) time, and the level of work-in-process (WIP). Value added time is the duration for a given job to be processed by trade contractors. However, a job is sometimes unattended and undergoes queuing (delay) time because all trades are fully utilized. Using cumulative figures for $V A$ and delays, completion time (CT) for an apartment is computed using Eq. (5):

$C T=\sum_{i=0}^{k}(V A+$ delays $)$

In Eq. (3), ' $k$ ' is the number of interacting trade contractors.

In the discrete event simulation (DES) experiments, trade contractors were not modeled individually but within the interconnected project network. At the first stage, construction production scenarios with different rework rates were analyzed. Each scenario was simulated for 100 times in order to achieve the desired statistical confidence level of 95\%. Construction processes were simulated for long periods in order to pass the transient behavior and reach a steady state. The results of running the simulation models have been shown in table 4.

Table 4. Project-level performance measures in different production scenarios

\begin{tabular}{lcccccccc}
\hline Parameter & \multicolumn{7}{c}{ Average time between activity starts $\left(\boldsymbol{t}_{\boldsymbol{a}}\right)=\mathbf{5}$ days } \\
\hline Probability of rework $(\boldsymbol{p})$ & $2 \%$ & $7 \%$ & $10 \%$ & $13 \%$ & $18 \%$ & $25 \%$ & $30 \%$ & $33 \%$ \\
Completion time $(\boldsymbol{C} \boldsymbol{T})$ & 115.79 & 133.33 & 146.67 & 162.96 & 200.00 & 293.33 & 440.00 & 628.57 \\
Value added $(\boldsymbol{V} \boldsymbol{A})$ time & 114 & 114 & 114 & 114 & 114 & 114 & 114 & 114 \\
Queuing time (delays) & 1.79 & 19.33 & 32.67 & 48.96 & 86 & 179.33 & 326 & 514.57 \\
Work-in-process $(\boldsymbol{W I P})$ & 21.00 & 24.18 & 26.60 & 29.56 & 36.27 & 53.20 & 79.80 & 114.00 \\
\hline
\end{tabular}

As can be seen, completion times nonlinearly increase in the production scenarios with higher rework probabilities. Furthermore, the level of work-in-process builds up and causes congestion in the trade network that further increases delays.

Project-level results are in line with those of the trade-level in the previous section and provide a measure of validation. The findings are consistent with the previous research (Alsehaimi, Koskela et al. 2013, Gündüz, Nielsen et al. 2013), indicating that workflow variability, caused by factors such as rework, is directly translated into long delays and late completions. 
239 Decreasing the activity start intervals in the simulation experiments worsened the performance 240 measures at the project level. Table 5 presents the results of running the simulation models in activity

241 start intervals are are reduced to four days instead of five days in the base case.

Table 5. Project-level performance measures resulting from reduced activity start intervals $\left(t_{a}\right)$

\begin{tabular}{lcccccccc}
\hline Parameter & \multicolumn{7}{c}{ Average time between activity starts $\left(\boldsymbol{t}_{\boldsymbol{a}}\right)=\mathbf{4}$ days } \\
\hline Probability of rework $(\boldsymbol{p})$ & $2 \%$ & $7 \%$ & $10 \%$ & $13 \%$ & $18 \%$ & $25 \%$ & $30 \%$ & $33 \%$ \\
Completion time $(\boldsymbol{C T})$ & 173.91 & 222.22 & 266.67 & 333.33 & 420.43 & 530.55 & 650.76 & 756.50 \\
Value added $(\boldsymbol{V} \boldsymbol{A})$ time & 114 & 114 & 114 & 114 & 114 & 114 & 114 & 114 \\
Queuing time (delays) & 59.91 & 108.22 & 152.67 & 219.33 & 306.43 & 416.55 & 536.76 & 642.5 \\
Work-in-process $(\boldsymbol{W I P})$ & 23.88 & 30.51 & 36.62 & 45.77 & 57.73 & 72.85 & 89.36 & 128.47 \\
\hline
\end{tabular}

243

244 Results in table 5 show that reducing the average time between activity starts, increases the work-inprocess level significantly. Furthermore, longer delays (non-value-added times) in table 5 than those in table 4, highlight a significant amount of waste in the production processes. In addition, a striking difference is observable in the completion times $(C T)$ by comparing the results in the two tables.

248 Since the average time between activity starts $\left(t_{a}\right)$ is shorter in table 5, any small increase in the workflow variability, caused by rework, nonlinearly inflates the $C T$. A comparison of the completion

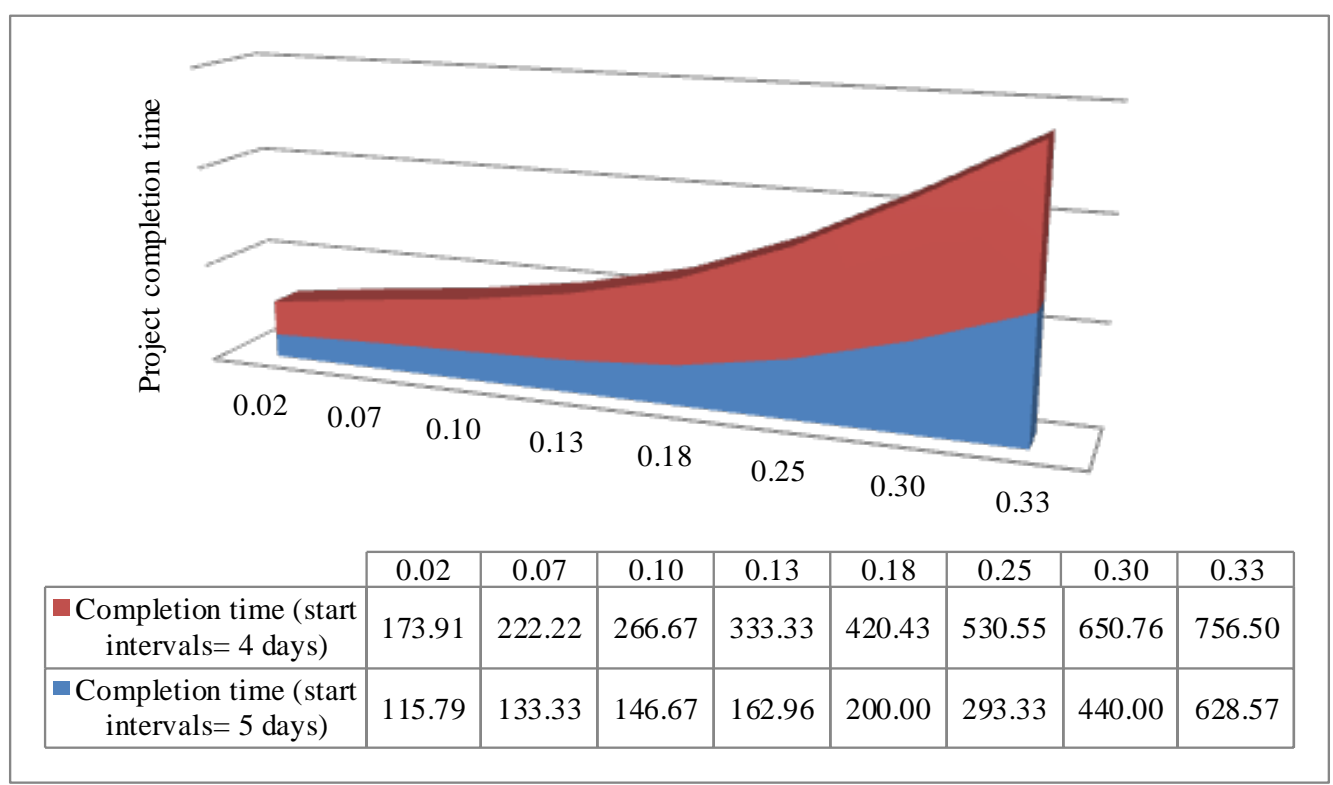


Results in table 5 show that decreasing $t_{a}$ causes the WIP level to grow in a chain reaction, resulting in delays caused by shortage of resources. In fact, construction production networks can become congested (due to higher WIP levels and longer delays) when the workflow is not stable. The findings extend those of Mitropoulos and Nichita (2010), and Liao, O'Brien et al. (2011), indicating that project managers should be extremely cautious about releasing excessive number of jobs to the network of trades especially when the workflow is subject to some kind of variability such as rework. In other words, solely focusing on process times at the expense of other production variables can be misleading.

\section{Conclusions}

Prior work has documented the negative impact of variability on performance metrics of construction projects. However such studies fall short of a holistic approach towards workflow variability and its impacts on both trade-level and project-level productivity and performance. In order to bridge this gap, this study quantitatively analyzed the impacts workflow variability on tangible performance metrics in several construction production scenarios. Towards this end, mathematical modeling at the trade level and discrete event simulation modeling at the project level were conducted to analyze the data.

The findings clearly show that construction performance and productivity are very sensitive to the interval of activity starts especially when workflow is subject to variability, caused by factors such as rework. That is, an increase in work quantities at the same time as trade involvement in process variability significantly inflates completion times resulting in workflow congestions and wasted time in the interconnected network of trades. These findings extend those of Hastak, Mullens et al. (2005) and El-Gohary and Aziz (2014), confirming that performance and productivity in the construction production can be improved through variability reduction approaches. In addition, control of workflow variability can streamline processes within the network of trades and avoid frequent work overloads or work starvations imposed on trade contractors. 


\section{Research contributions and opportunities for future research}

279 This work contributes to the body of knowledge in engineering management by developing an insight 280 into the dynamics of workflow variability and its impact on construction productivity and performance. Most notably it is one of few studies to our knowledge that takes a holistic approach towards analysis of both trade-level and project-level performance using two modeling approaches. The results provide compelling evidence that excessive system loading together with workflow variability results in work congestions and productivity loss. It is suggested that project managers avoid assigning excessive levels of work quantities to trade contractors when the workflow is subject to variability.

This study reveals the tip of the iceberg in performance-related issues in the construction production. Further research should analyze other management-related variables that affect the construction production and identify feasible interventions in order to control their effects on performance and productivity. Furthermore, variability and its effects on the entire supply chain of Architectural,

Engineering and construction (AEC) projects should also be modeled and analyzed.

\section{References}

AbouRizk, H. and S. Hague (2009). An overview of the COSYE environment for construction simulation. Proceedings of the 2009 Winter Simulation Conference (WSC).

Ahmad, I. (1999). "Managing, processing, and communicating information: what A/E/C organizations should know." Journal of Management in Engineering 15(4): 33-36.

Alsehaimi, A., L. Koskela and P. Tzortzopoulos (2013). "Need for alternative research approaches in construction management: Case of delay studies." Journal of Management in Engineering 29(4): 407-413.

Arashpour, M., M. Shabanikia and M. Arashpour (2012). "Valuing the contribution of knowledgeoriented workers to projects: a merit based approach in the construction industry." Australasian Journal of Construction Economics and Building 12(4): 1- 12.

Arashpour, M., R. Wakefield and N. Blismas (2013). Improving construction productivity: implications of even flow production principles. CIB World Building Congress 2013: Construction and Society, Queensland University of Technology.

Arashpour, M., R. Wakefield, N. Blismas and E. Lee (2014). "Analysis of Disruptions Caused by Construction Field Rework on Productivity in Residential Projects." Journal of Construction Engineering and Management: doi:10.1061/(ASCE)CO.1943-7862.0000804

Back, W. E. and L. C. Bell (1995). "Monte Carlo simulation as tool for process reengineering." Journal of Management in Engineering 11(5): 46-53.

Barriga, E. M., J. G. Jeong, M. Hastak and M. Syal (2005). "Material control system for the manufactured housing industry." Journal of Management in Engineering 21(2): 91-98.

Castro-Lacouture, D., G. A. Süer, J. Gonzalez-Joaqui and J. K. Yates (2009). "Construction project scheduling with time, cost, and material restrictions using fuzzy mathematical models and 
critical path method." Journal of Construction Engineering and Management 135(10): 10961104.

Doloi, H., K. Iyer and A. Sawhney (2011). "Structural equation models for assessing impacts of contractor's performance on project success." International Journal of Project Management 29(6): 687-695.

El-Adaway, I. H. (2012). "Insurance pricing for windstorm-susceptible developments: Bootstrapping approach." Journal of Management in Engineering 28(2): 96-103.

El-Gohary, K. M. and R. F. Aziz (2014). "Factors influencing construction labor productivity in Egypt." Journal of Management in Engineering 30(1): 1-9.

Golob, K., M. Bastič and I. Pšunder (2013). "Influence of project and marketing management on delays, penalties, and project quality in slovene organizations in the construction industry." Journal of Management in Engineering 29(4): 495-502.

Gündüz, M., Y. Nielsen and M. Özdemir (2013). "Quantification of delay factors using the relative importance index method for construction projects in Turkey." Journal of Management in Engineering 29(2): 133-139.

Han, S. H., S. H. Park, E. J. Jin, H. Kim and Y. K. Seong (2008). "Critical issues and possible solutions for motivating foreign construction workers." Journal of Management in Engineering 24(4): 217-226.

Hastak, M., M. A. Mullens and M. Syal (2005). National housing research agenda for construction management and production. Construction Research Congress: Broadening Perspectives, San Diego, CA.

Hopp, W. J. and M. L. Spearman (2008). Factory physics, McGraw-Hill Irwin Irwin.

Hwang, B. G., X. Zhao and K. J. Goh (2013). "Investigating the client-related rework in building projects: The case of Singapore." International Journal of Project Management.

Jarkas, A. M. and M. Radosavljevic (2013). "Motivational factors impacting the productivity of construction master craftsmen in Kuwait." Journal of Management in Engineering 29(4): 446454.

Josephson, P. E., B. Larsson and H. Li (2002). "Illustrative benchmarking rework and rework costs in Swedish construction industry." Journal of Management in Engineering 18(2): 76-83.

Kingman, J. F. C. (1992). Poisson processes, Oxford university press.

Laufer, A., H. Woodward and G. A. Howell (1999). "Managing the decision-making process during project planning." Journal of Management in Engineering 15(2): 79-84.

Lee, E. W. M., I. W. H. Fung, V. W. Y. Tam and M. Arashpour (2013). "A fully autonomous kernelbased online learning neural network model and its application to building cooling load prediction." Soft Computing: 1-16.

Liao, P. C., W. J. O'Brien, S. R. Thomas, J. Dai and S. P. Mulva (2011). "Factors affecting engineering productivity." Journal of Management in Engineering 27(4): 229-235.

Liu, M., G. Ballard and W. Ibbs (2011). "Work flow variation and labor productivity: Case study." Journal of Management in Engineering 27(4): 236-242.

Love, P. E. D. and J. Smith (2003). "Benchmarking, benchaction, and benchlearning: Rework mitigation in projects." Journal of Management in Engineering 19(4): 147-159.

Mahamid, I., A. Bruland and N. Dmaidi (2012). "Causes of delay in road construction projects." Journal of Management in Engineering 28(3): 300-310.

Mawhinney, M. (2008). International construction, Wiley. com.

Min, J. U. and H. C. Bjornsson (2008). "Agent-based construction supply chain simulator (CS2) for measuring the value of real-time information sharing in construction." Journal of Management in Engineering 24(4): 245-254.

Mitropoulos, P. and T. Nichita (2010). "Critical concerns of production control system on projects with labor constraints: Lessons from a residential case study." Journal of Management in Engineering 26(3): 153-159.

Mubarak, S. (2010). Construction project scheduling and control, Wiley.

Palaniappan, S., A. Sawhney, H. H. Bashford and K. D. Walsh (2007). Special purpose simulation template for workflow analysis in construction. Winter Simulation Conference, Washington, DC. 
Shoura, M. M. and A. Singh (1997). "System interrelations of organizational variables." Journal of Management in Engineering 13(1): 67-79.

Tommelein, I., D. Riley and G. Howell (1999). "Parade Game: Impact of Work Flow Variability on Trade Performance." Journal of construction engineering and management 125(5): 304-310.

Trietsch, D. and K. R. Baker (2012). "PERT 21: Fitting PERT/CPM for use in the 21st century." International Journal of Project Management 30(4): 490-502.

Ummer, N., U. Maheswari, V. A. Matsagar and K. Varghese (2014). "Factors influencing design iteration with a focus on project duration." Journal of Management in Engineering 30(1): 127130.

Wang, W. C. (2004). "Supporting project cost threshold decisions via a mathematical cost model." International Journal of Project Management 22(2): 99-108.

$\mathrm{Yu}, \mathrm{H}$. (2011). An integrated approach toward lean for production homebuilders, PhD dissertation, University of Alberta.

Yung, P. and B. Yip (2010). "Construction quality in China during transition: A review of literature and empirical examination." International Journal of Project Management 28(1): 79-91. 